\title{
GETTING RESPONSIBLE TRAVELLERS ON BOARD
}

\author{
GIULIO PATTANARO \\ Independent Researcher
}

\begin{abstract}
In times of growing global concern over the effects of climate change, railways could potentially provide the market with viable and valuable options for more environmentally-friendly responsible tourism practices. Traditional train companies themselves appear to be increasingly aware of the immense tourism potential of their sector; this is evidenced by their offer of additional - and often complementary - tourist-oriented services such as car rental bargains or combined transportaccommodation packages on top of conventional train tickets. The present paper aims to examine the marketing tools and initiatives that train companies have conceived and developed to target and attract responsible travellers. It reviews the most relevant literature on rail tourism, with a focus on both the main characteristics of rail tourists and the link between rail tourism and sustainability. The literature review will be followed by the analysis of the tools and initiatives being implemented by three national train operating companies - Société Nationale des Chemins de Fer (SNCF), Swiss Federal Railways (SBB-CFF-FFS) and Trenitalia in France, Switzerland and Italy respectively. The case study analysis is based on the inputs collected from each of the three operator's corporate sustainability strategy, business-to-consumer (B2C) website, and digital or printed promotional material provided to potential or actual passengers. The findings relative to each train operator will eventually be compared and some conclusions on the main components and outreach of the strategies and initiatives put in place by train operators to attract responsible tourists will be drawn. The paper will conclude by suggesting further research on the topic and the analysis of additional case studies.
\end{abstract}

Keywords: rail transport, rail tourism, responsible traveller, train companies, sustainable mobility.

\section{INTRODUCTION}

To reach a given tourism destination by train may be particularly attractive for those travellers who prefer environmentally-friendly means of transport.

For their part, traditional train companies - many of which used to be state-owned companies operating in a monopolistic market - have become more and more aware of the tourism potential of their product. This is why, next to conventional train tickets, they have come to offer additional and complementary tourist-oriented services like car rental and hotel booking.

This paper analyses the strategies and marketing tools some train companies put in place, as well as the products and services they propose in order to target and attract responsible travellers.

A review of the most relevant literature on rail tourism will be carried out, staying focussed on the features of the rail-tourism key players and the link between rail tourism and sustainability.

The literature review will be followed by the analysis of the tools and initiatives implemented by three national train companies operating in Europe: the Société Nationale des Chemins de Fer (SNCF), France, the Swiss Federal Railways (SBB-CFF-FFS), Switzerland, and Trenitalia, Italy. The case study analysis will take into account each operator's corporate sustainability strategy, business-to-consumer (B2C) website, and digital or printed promotional material provided to potential or actual passengers.

Eventually, a comparative analysis of the case study will lead to drawing some conclusions on the key elements of the strategies and initiatives applied by train companies to attract responsible tourists and their effective marketing power. 


\section{LITERATURE REVIEW}

Having briefly mentioned the relation between transport and tourism, the present literature review will focus on the key stakeholders of rail tourism: on the one hand, train companies; on the other hand, train tourists. Particular attention will be paid to a specific group of rail tourists - the responsible travellers - thus paving the way to exploring the link between rail tourism and sustainability.

\subsection{Rail transport and tourism}

Transport plays a crucial role in tourism development: not only do good transport infrastructures ease the tourists' transfer from their place of origin to their holiday destination, but convenient transport connections and facilities turn out to be a key selection criteria for the choice of the destination itself [1]. Transportation and transport operators are therefore constituent parts of the overall destination product and, as such, they get to influence both the management and the marketing of the destination itself [2].

In the 19th century, the advent of railways made it possible to develop the first popular tourism destinations [3]. Nowadays, high-speed railways are expected to benefit the local economy of the urban areas located all along the railway line by bringing leisure and business tourists and engaging new tourism-driven companies [4]-[7].

\subsection{Train operating companies and tourism}

Same as for conventional train lines, high-speed railways are exploited by the so-called train operating companies (TOCs), i.e. the rail operators responsible for running trains. It is worth mentioning that TOCs do not manage the railway infrastructure facilities: as a matter of fact, the facilities are owned and overseen by one single company - usually a public company, whereas TOCs can be state-owned or fully private - depending on the countries where they operate - and they may or may not compete with other companies offering the same service [8], [9].

While TOCs' core business is to provide train rides, irrespective of the type of travel (business travel, leisure journey, family visits, and thus on), the rail market includes also operators focussed exclusively on rail tourism. Analysing rail tourism in France, Blancheton and Marchi [10] identify three categories of operators associated with rail tourism. The first category makes reference to train companies that own their rolling stock and enjoy dedicated railway lines - including tourist railways, meter-gauge railways and lines with tourism potential. The second category comprises train companies and non-profit associations that possess their rolling stock (e.g. iconic trains like the Orient Express) but make use of railway lines owned and managed by another entity. The third category of rail-tourism operators corresponds to those operators that sell rail-tourism trips and packages, without counting on either their own rolling stock or railway lines.

It is important to highlight that the present paper considers as "train companies" only TOCs. This is because the paper's ultimate objective is to understand through what actions and initiatives conventional train operators - not necessarily used to dealing with tourism are seeking to attract responsible travellers and meet their needs.

\subsection{Rail tourists and responsible travellers}

Many different reasons and motivations may lead travellers to move by train.

For some travellers, the train and railways themselves constitute the main attraction, and therefore the main purpose, of their journey [10], [11]. This is the case, for instance, of 
tourists who choose world-famous train experiences like the Trans-Siberian railway or the scenic railways across the Swiss Alps. Because of their non-mass peculiar tourism preferences, these travellers are representative of special interest tourism [12] and become the main market target for the three categories of rail tourism operators identified in France by Blancheton and Marchi [10].

However, even without showing a strong interest in trains and railways, travellers may still prefer the train to other modes of transport. And this for a variety of reasons: the train can be the fastest and most convenient way to reach a destination; the train often takes passengers to the very city centre, thus avoiding traffic congestion and parking issues; the price of a train ticket is potentially more competitive and value-for-money than the price of the alternative flight option, etc. Literature has analysed these elements extensively [3], [4], [5], [7], [13]-[16], also with a view to identifying likely tourism opportunities linked to the flows of travellers - for instance, business travellers - reaching their destinations by train. The same literature points out how some train companies have eventually recognised the tourism potential of train travellers and, based on this, are now competing by complementing conventional train tickets with tourism-related service and products [7], [14], [17].

Regardless of the distance to cover or the price to pay, some could prefer to reach their destination by train simply out of a necessity to slow down and enjoy the journey experience itself (e.g. landscapes, tranquillity, enriching dialogues, etc.). In this sense, travelling by train joins the so-called slow tourism [18]-[21]. By opting for a slower means of transport and almost inevitably limiting the number of places and attractions to visit over the trip time, travellers may actually get to live a more intense experience and connect and engage more with the locals. As it was observed by Lyons et al. [22], the vast majority of leisure rail passengers tend to value side and so-to-say intangible experiences such as conversations with travel mates, informal exchanges with co-travellers, window gazing and people watching.

Slow tourism literature shows that the predilection for a slower mode of travel frequently comes alongside environmentally-friendly travel concerns in general. A point of contact that allows to connect slow tourism with responsible travelling and bring this paper into focus.

From a sustainable mobility perspective, the responsible traveller is someone who is willing to replace her/his old mobility habits with more sustainable alternatives, mainly based on the fact that for him/her a more environmentally-friendly lifestyle represents an aspirational goal [23]. The perception of environmental threats is indeed a key factor when it comes to pushing individuals to opt for greener modes of transport [24]. In the current context of growing global concern over the effects of climate change - including the so-called ecoanxiety [25], [26] i.e. the spreading anxiety associated with the negative effects of the ecological crisis - and based on the lower carbon footprint of the train as opposed to other modes of transport [27], [28], responsible travellers opting for the rail are likely to grow in numbers. Quite illustrative is the case of Sweden: in parallel with the rise and spread of the flight shame movement, the train bragging movement is taking hold in the country [26], [29]. As for dissemination and awareness raising on a larger scale, the global press is publishing more and more articles on the possibility to shift from the plane to the rail and the immediate environmental benefits of it, for example [30]-[32].

How responsible travelling is not just about travelling greener, though, is testified to by the feedback given by flight shame-movement train travellers in Sweden [29], the aforementioned literature on slow tourism [18]-[21] and studies on green tourists, for example [33], [34]. When responsible travellers engage on a leisure journey, there is evidence that they tend to prefer and enjoy unconventional tourism experiences: they stay in ecofriendly accommodation and seek activities with low impact on the environment and ecofriendly accommodation, they care about local culture and local products and they value the 
time spent in interacting with the locals. In short, their attitude seems to go beyond the environmental concerns and encompass all facets of sustainability.

Looking at the way traditional train companies are trying to take responsible travellers on board is the purpose of this paper.

\section{METHODOLOGY}

This paper analyses the strategies and marketing tools, as well as the dedicated products and services, through which traditional train companies are targeting and attracting responsible travellers. The analysis covers three national train companies operating in Europe: the Société Nationale des Chemins de Fer (SNCF) in France, the Swiss Federal Railways (SBB-CFFFFS) and Trenitalia-Ferrovie dello Stato Italiane (Trenitalia) in Italy. The author singled out these three traditional European train operators based on his familiarity with the rail system in the respective countries and on the languages used in the companies' websites, reports and promotional materials.

The case study analysis takes into account each operator's most recent corporate sustainability strategy, business-to-consumer (B2C) website, and digital or printed promotional material provided to potential or actual passengers. All these sources have undergone consultation and review, in an effort to understand if the three train companies have actually envisaged and implemented specific actions and initiatives for reaching out to responsible travellers.

The findings of the case study analysis will be discussed and some conclusions will be drawn.

\section{FINDINGS}

The results of the case study analysis have been articulated into three separate sections. The first section will show how each company's corporate sustainability strategy deals with responsible travellers. The second section will illustrate through what channels the three companies are reaching out to responsible travellers. The last section will look at the products and services specifically dedicated to responsible travellers.

\subsection{Responsible travellers from a corporate sustainability perspective}

It must be said that responsible travellers as such are not mentioned explicitly in any of the three analysed corporate sustainability strategies [35]-[37]. However, the three train companies are clearly committed to both promoting sustainable mobility practices and meeting the expectations of a growing number of environmentally concerned consumers. Another common element of the three corporate sustainability strategies is the reference made to the Paris Agreement on Climate Change and the UN 2030 Agenda for Sustainable Development with its 17 Sustainable Development Goals.

In terms of promoting sustainable mobility practices, the three companies are investing in specific environmental targets such as the gradual reduction of energy, water and waste consumption and the promotion of green procurement and circular-economy solutions. A set of indicators to monitor the achievement of these environmental targets has been put in place. Moreover, the three operators are raising awareness about the train's relative low carbon emissions - in comparison, for example, with the plane. Through some partnership arrangements with external companies, and in order to minimise the journey's overall carbon footprint, the three companies are also giving their customers the option of combining different low-emission modes of transport, e.g. train for long distances and road public transportation for urban or local displacements, directly on their online booking platforms. 
In particular, the SBB-CFF-FFS stresses the importance of proposing captivating discounted fares to individual passengers with access to private cars or other more polluting alternatives. Further proof of the commitment to actively promoting sustainability is Trenitalia's yearly campaign Treno Verde ("Green Train"), which, in cooperation with the Italian environmental protection association Legambiente, encourages environmentally-friendly practices on board a dedicated train [38].

From a marketing perspective, most of the above-mentioned measures and initiatives are a way to attract new customers and/or reinforce the loyalty of regular or long-term users. No doubt that the target audience comprises environmentally concerned customers, who also constitute the target audience of other initiatives within the companies' marketing plans. As a way of example, the SNCF works to meet the expectations of environmentally conscious customers by serving local organic food on board some of its trains, while Trenitalia encourages slow tourism by revitalising historic railways promoting local culture and local food tradition. Unfortunately, no figures or subscribers' evaluation forms are reported and published in the corporate sustainability strategy of either company, and the same applies to SBB-CFF-FFS.

\subsection{Ways to reach out to responsible travellers}

The channels through which the three companies seek to reach out to responsible travellers do not essentially differ from the well-established hooks deployed to captivate conventional users, i.e. app, phone number, social media, train station counters, travel agencies, B2C website. All these tools give the opportunity to ask for information and perform bookings. In particular, the B2C website of each of the three companies [39]-[41] is available in several languages and tends to adapt highlights and bargains to the user-selected language. For example, by choosing English as website browsing language, the web user and potential customer is displayed travelling options mainly tailored to non-domestic international travellers. In the case of SNCF and Trenitalia, content customisation applies also to languages other than English: for instance, when consulting the SNCF B2C website in Italian, the train connections between Italy and France come out among the first results. For the time being, what appears to be missing is the customisation of content based on the type of travellers and their main features. In an attempt to become more user-friendly, though, the homepage of the SBB-CFF-FFS' B2B website allows for the selection of the desired travel experience (i.e. city trips, wellness, festivals, etc.), so as to orient the user and adapt the content.

The three train operators reach out to customers also through printed materials: the SBBCFF-FFS publishes printed brochures and information leaflets, as well as an on-board magazines; the SNCF seems to invest more in information leaflets, whereas Trenitalia mainly counts on on-board magazines available on long-distance high-speed trains. According to the promotional printed material collected by the author, most information on sustainable mobility and sustainable travelling can be found in the on-board magazines: from enjoyable articles suggesting natural immersion gateways to visual adverts for cultural discovery weekends.

Speaking of promotion of sustainable mobility practices, it is worth reporting Trenitalia's commitment to informing their high-speed passengers of the estimated amount of kilograms of carbon dioxide saved thanks to her/his choice to take the train instead of the car or the plane. The amount of saved $\mathrm{CO}_{2}$ is revealed on both Trenitalia's digital and printed version of the train ticket. 


\subsection{Products and services tailored to responsible travellers}

On top of conventional train tickets, the three train companies taken into consideration in this study are giving then train traveller the opportunity to build up a full - and green - tourism experience by proposing additional multi-operator and multi-experience travel combinations. Multi-operator and multi-experience combinations which are often the result of some partnership agreements with external providers and comprise hotel booking, car rentals, luggage shipping or even car-/bike-/scooter-sharing in a given geographical area. SBB-CFFFFS and Trenitalia go even further, by proposing the direct booking of museum tickets and guided tours.

The provision of environmentally- and user-friendly options, e.g. combination of train and other low-emission travel or cultural experiences, show how the three train companies strive to open up rail tourism in general and responsible rail travellers more in particular. The three companies' awareness of the preferences of responsible travellers can be inferred from the analysis of their corporate sustainability strategy, with relevance given to aspects like the provision of locally-sourced organic food on board (SNCF) and the discovery of regional culture and traditions through the revitalisation of historic railways (Trenitalia). In the case of SBB-CFF-FFS, the care for sustainable travelling is reflected in both the B2C website and the printed materials, where the Swiss operator adverts day tours or short holidays by rail evoking nature, eco-friendly activities and responsible tourism in general.

\section{DISCUSSION}

The analysis of the sustainability strategy, the B2C website and the promotional material of the three train companies considered in the context of this paper shows that train operators have become aware of the growing concern over climate change and environmental protection. It can be said that train companies are committed to actively contributing to the implementation of the 17 Sustainable Development Goals and the Paris Agreement on Climate Change. In line with this, they have set targets for on-board energy, water and waste reduction and they have developed specific indicators to monitor and assess the achievement of these targets. Awareness-raising initiatives - such as the promotion of sustainable mobility practices through their on-board magazines - have been also elaborated and implemented.

In addition to raising awareness about environmental issues, these steps towards sustainability can also be looked at as powerful marketing tools to attract new customers and/or increase the loyalty of existing ones. In times of growing global concern over the effects of climate change and eco-anxiety, rail operators seem to be willing to capitalise on the environmentally-friendly reputation of modern trains. To emphasise the low carbon footprint of train travelling as opposed to cars or planes is an influential way to reach out to responsible travellers, i.e. travellers not only fighting for green mobility but also looking for slower, sustainable and locally-embedded tourism opportunities.

The channels used by train companies to get in contact and interact with responsible travellers are the same as the ones used to dialogue with conventional customers, i.e. apps, phone numbers, social medias, train station counters, travel agencies, the B2C website and digital or printed promotional materials. Although not specifically designed for responsible travellers, these channels display very interesting products and services for tourists planning sustainable trips or even vacations. This can be the case of cultural discovery train journeys offers and train- and bike-sharing combinations. In spite of all this, though, it is difficult - if not impossible - at this stage to gather figures on how many travellers are buying or considering buying these products and services. 
The information currently available in the sources consulted by the author in the context of this research does not allow for a comprehensive analysis of the size and evolution of the responsible rail tourism market segment. Corporate reports limit themselves to presenting figures related to train rides and train passengers in general, without indicating the reasons, motivations or purposes behind individual or group trips. This might depend on the lack of surveys and questionnaires aimed at collecting and clustering users' features. Moreover, the companies' B2C websites do not provide for user-dedicated access or content, thus limiting customised content to language-driven results only.

\section{CONCLUSION}

The growing global concern over the effects of climate change is seriously affecting people's preferences in terms of mobility. Despite the step back in the use of public transport in the short term mainly due to COVID-19 [42], sustainable modes of transport are expected to come out on top in the long term. In addition to opting for more environmentally-friendly means of transport, though, responsible travellers are also looking for slower, locallyembedded and overall sustainable tourism experiences.

This work has shown that traditional train companies are aware of the considerable potential of the train in attracting responsible travellers. They have set environmental targets and they are actively raising awareness about the lower carbon footprint of train trips as opposed to other mobility options. Furthermore, on their conventional ticket booking platforms they are offering a number of complementary products and services, e.g. train and bike combinations and historic railway journeys, likely to catch the eye of both ordinary tourists and responsible travellers.

Yet, conventional train companies like the ones examined within the framework of this paper do not seem to be fully equipped to identify the needs of responsible travellers and monitor the evolution of their market segment. The figures published by train operators report on train rides and train passengers only, without specifying the train users' characteristics and reasons for travelling. To the same extent, no online survey or any similar tool have helped to profile the visitors and users of the companies' B2C website. Such an initiative could certainly lead to more targeted marketing decisions.

Train operators would certainly benefit from further research on the topic, too. There is a need for analysis of more case studies on rail tourism, if possible including interviews with both train operators' managers and users. Interviews with train companies' managers in particular should aim to deepen the knowledge about (i) the current and future strategies targeting responsible travellers, (ii) the potential networking and partnership activities with specialised tour operators, and (iii) the measures and indicators used to monitor the performance of responsible travellers-related initiatives.

\section{REFERENCES}

[1] Prideaux, B., The role of the transport system in destination development. Tourism Management, 21(1), pp. 53-63, 2000.

[2] Buhalis, D., Marketing the competitive destination of the future. Tourism Management, 21(1), pp. 97-116, 2000.

[3] Michniak, D., Role of railway transport in tourism: Selected problems and examples in Slovakia. Quaestiones Geographicae, 35(4), pp. 107-120, 2016.

[4] Albalate, D. \& Fageda, X., High speed rail and tourism: Empirical evidence from Spain. Transportation Research Part A: Policy and Practice, 85, pp. 174-185, 2016. 
[5] Delaplace, M., Pagliara, F., Perrin, J. \& Mermet, S., Can high speed rail foster the choice of destination for tourism purpose. Procedia-Social and Behavioral Sciences, 111(1), pp. 166-175, 2014.

[6] Masson, S. \& Petiot, R., Can the high speed rail reinforce tourism attractiveness? The case of the high speed rail between Perpignan (France) and Barcelona (Spain). Technovation, 29(9), pp. 611-617, 2009.

[7] Yang, Y., Li, D. \& Li, X., Public transport connectivity and intercity tourist flows. Journal of Travel Research, 58(1), pp. 25-41, 2019.

[8] Jeffcott, S., Pidgeon, N., Weyman, A. \& Walls, J., Risk, trust, and safety culture in UK train operating companies. Risk Analysis, 26(5), pp. 1105-1121, 2006.

[9] Luan, X., Corman, F. \& Meng, L., Non-discriminatory train dispatching in a rail transport market with multiple competing and collaborative train operating companies. Transportation Research Part C: Emerging Technologies, 80, pp. 148-174, 2017.

[10] Blancheton, B. \& Marchi, J.-J., The three systems of rail tourism: French case. Tourism Management Perspectives, 5, pp. 31-40, 2013.

[11] Nering, N. \& Feger, J.E., Competitiveness factors of tourist train operator in Brazil. Podium Sport, Leisure and Tourism Review, 8(1), pp. 81-97, 2019.

[12] Trauer, B., Conceptualizing special interest tourism: Frameworks for analysis. Tourism Management, 27(2), pp. 183-200, 2006.

[13] Dallen, J., The challenges of diverse visitor perceptions: rail policy and sustainable transport at the resort destination. Journal of Transport Geography, 15(2), pp. 104115, 2007.

[14] Delaplace, M. \& Dobruszkes, F., From low-cost airlines to low-cost high-speed rail? The French case. Transport Policy, 38, pp. 73-85, 2015.

[15] Moyano, A., Rivas, A. \& Coronado, J.M., Business and tourism high-speed rail sameday trips: Factors influencing the efficiency of high-speed rail links for Spanish cities. European Planning Studies, 27(3), pp. 533-554, 2019.

[16] Wu, N., Qiu, Y. \& Chen, L., Research on marketing strategy of intercity railway in Wuhan metropolitan area. Advances in Economics, Business and Management Research, 68, pp. 650-657, 2019.

[17] Prideaux, B., Tracks to tourism: Queensland rail joins the tourist industry. International Journal of Tourism Research, 1(2), pp. 73-86, 1999.

[18] Caffyn, A., Advocating and implementing slow tourism. Tourism Recreation Research, 37(1), pp. 77-80, 2012.

[19] Dickinson, J.E., Robbins, D. \& Lumsdon, L., Holiday travel discourses and climate change. Journal of Transport Geography, 18(3), pp. 482-489, 2010.

[20] Lumsdon, L.M. \& McGrath, P., Developing a conceptual framework for slow travel: A grounded theory approach. Journal of Sustainable Tourism, 19(3), pp. 265-279, 2011.

[21] Oh, H., Assaf, A.G. \& Baloglu, S., Motivations and goals of slow tourism. Journal of Travel Research, 55(2), pp. 205-219, 2016.

[22] Lyons, G., Jain, J. \& Holley, D., The use of travel time by rail passengers in Great Britain. Transportation Research Part A: Policy and Practice, 41(1), pp. 107-120, 2007.

[23] Holden, E., Banister, D., Gössling, S., Gilpin, G. \& Linnerud, K., Grand narratives for sustainable mobility: A conceptual review. Energy Research and Social Science, 65, 2020 . 
[24] Wang, S., Wang, J. \& Yang, F., From willingness to action: Do push-pull-mooring factors matter for shifting to green transportation? Transportation Research Part D: Transport and Environment, 79, 2020.

[25] Ingle, H.E. \& Mikulewicz, M., Mental health and climate change: Tackling invisible injustice. The Lancet Planetary Health, 4(4), e128-e130, 2020.

[26] Mkono, M., Eco-anxiety and the flight shaming movement: Implications for tourism. Journal of Tourism Futures, 2020.

[27] Givoni, M., Environmental benefits from mode substitution: Comparison of the environmental impact from aircraft and high-speed train operations. International Journal of Sustainable Transportation, 1(4), pp. 209-230, 2007.

[28] Wickizer, B.J. \& Snow, A., Rediscovering the transportation frontier: Improving sustainability in the United States through passenger rail. Sustainable Development Law and Policy, 11(1), pp. 12-16, 2011.

[29] Jacobson, L., Åkerman, J., Giusti, M. \& Bhowmik, A.K., Tipping to staying on the ground: Internalized Knowledge of climate change crucial for transformed air travel behavior. Sustainability, 12(5), pp. 1-18, 2020.

[30] Birnbaum, M., Europe's flight-shame movement has travelers taking trains to save the planet. The Washington Post, 2 Aug. 2019. www.washingtonpost.com/world/europe/ europes-flight-shame-movement-has-travelers-taking-trains-to-save-the-planet/2019/ 08/02/1bd38486-ac96-11e9-9411-a608f9d0c2d3_story.html. Accessed on: 2 Jun. 2020.

[31] Gardner, N., No need to fly: Three European trips easier by train. The Guardian, 13 Jan. 2020. www.theguardian.com/travel/2020/jan/13/rail-itineraries-europe-tarianholidays-austria-netherlands-coast-france-burgundy-vineyards. Accessed on: 2 Jun. 2020.

[32] Vaudano, M. \& Sénécat, A., Quels trajets intérieurs en avion pourraient être interdits en cas d'alternative en train? Le Monde, 8 Jun. 2019. www.lemonde.fr/les-decodeurs/ article/2019/06/07/la-majorite-des-vols-interieurs-pourrait-se-faire-en-train-et-ceserait-bon-pour-l-environnement_5472992_4355770.html. Accessed on: 2 Jun. 2020.

[33] Dolnicar, S., Crouch, G.I. \& Long, P., Environment-friendly tourists: what do we really know about them? Journal of Sustainable Tourism, 16(2), pp. 197-210, 2008.

[34] Falk, M. \& Hagsten, E., Ways of the green tourist in Europe. Journal of Cleaner Production, 225, pp. 1033-1043, 2019.

[35] SBB-CFF-FFS SA, Rapporto di gestione delle FFS 2019. https://company.sbb.ch/ content/dam/internet/corporate/it/medien/publikationen/geschaeftsbericht/SBBGeschaeftsbericht-2019.pdf.sbbdownload.pdf. Accessed on: 6 Jun. 2020.

[36] SNCF, 2018 Corporate social engagement report, Direction du développement durable. https://medias.sncf.com/sncfcom/finances/Publications_Groupe/SNCFRSE_english.pdf. Accessed on: 25 May 2020.

[37] Ferrovie dello Stato Italiane, Group Strategy, Planning, Innovation and Sustainability Department, 2018 Sustainability report: The journey goes on. www.fsitaliane.it/ content/dam/fsitaliane/en/Documents/commitment/sustainability-report/2018sustainability-report-/2018SR\%20-\%20Executive\%20Summary.pdf. Accessed on: 5 Jun. 2020.

[38] Treno Verde, Legambiente Onlus. www.trenoverde.it. Accessed on: 8 Jun. 2020.

[39] OUI.SNCF, Société Nationale des Chemins de Fer (SNCF). https://en.oui.sncf/en. Accessed on: 8 Jun. 2020.

[40] SBB-CFF-FFS, Swiss Federal Railways (SBB-CFF-FFS). www.sbb.ch/en/home.html. Accessed on: 8 Jun. 2020. 
126 Sustainable Tourism IX

[41] Trenitalia, Trenitalia-Ferrovie dello Stato Italiane. www.trenitalia.com. Accessed on: 8 Jun. 2020.

[42] Leenen, M., Remainder of 2020 looks bleak for rail. International Railway Journal, 3 Jun. 2020. www.railjournal.com/in_depth/remainder-of-2020-looks-bleak-for-rail. Accessed on: 11 Jun. 2020. 